DOI: $\underline{\text { http://dx.doi.org/10.5007/1980-3532.2015n13p96 }}$

\title{
Estabelecidos e outsiders: trabalhando elementos de história, cultura e sociedade numa obra clássica
}

\section{Established and outsiders: working elements of history, culture and society in a classic work}

\author{
Marcelo da Silva Araujo \\ Doutor em Antropologia (UFF) \\ Professor de Sociologia do Colégio Pedro II \\ msaraujo@cp2.g12.br
}

\begin{abstract}
Resumo: Originalmente escrito como trabalho final de curso de doutorado, este texto busca colaborar para o desvelamento de uma obra seminal sobre violência, dominação simbólica, discriminação e exclusão, articulando três dimensões essenciais (história, cultura e sociedade) dentro da pesquisa em ciências sociais, notadamente da Antropologia e da Sociologia. Não pretendendo ser uma resenha ou sucessão de comentários acerca do clássico, o artigo propõe-se a pensar que conexões e descobertas se pode fazer em um texto cuja contribuição parece ter sido, após 41 anos de sua publicação, escrutinada ao máximo, revelando, com o olhar focado nas referidas dimensões, outros modos de utilizá-lo no trabalho acadêmico.
\end{abstract}

Palavras-chave: Estabelecidos e outsiders. Pesquisa e trabalho acadêmico. História. Cultura. Sociedade.

Abstract: Originally written as a final work of $\mathrm{PhD}$ course, this text seeks to contribute to the unveiling of a seminal work on violence, symbolic domination, discrimination and exclusion, combining three essential dimensions (history, culture and society) in the research in the social sciences, notably anthropology and sociology. Not intended to be a review or succession of comments about the classic, the article proposes to think that the connections and findings can be made from a text whose contribution seems to have been, after 41 years of its publication, scrutinized the maximum, revealing, with his eyes focused on these dimensions, other ways to use it in academic work.

Keywords: Established and outsiders. Research and academic work. History. Culture. Society.

Originais recebidos em: 19/02/2016

Aceito para publicação em: 20/05/2016

Revista Em Debate (UFSC), Florianópolis, volume 13, p. 96-110, 2015. ISSNe 1980-3532 


\section{Introdução}

O livro Os estabelecidos e os outsiders foi originalmente publicado em língua inglesa em 1965. Seu sucesso motiva, até hoje, comentários e utilizações como fundamentação de muitos estudos envolvendo a violência ou dominação simbólica, a discriminação e a exclusão. Único livro propriamente etnográfico de Norbert Elias, em parceria com o professor John Scotson, a abordagem do poder, constante no subtítulo do mesmo, surge como aspecto essencial e constante em todos os textos que se debruçaram sobre ele.

Não é necessário detalhar o tema do livro nem sua ambientação mais contextual. Contudo, importa relembrar que a obra é fruto de um estudo realizado em fins da década de 1950 e inícios da de 1960 na comunidade fictícia de Winston Parva, próxima de Leicester, na Inglaterra. Originalmente pensada pelo professor da escola básica local John Scotson com a finalidade de compreender e tratar do problema da delinquência juvenil naquela localidade, a pesquisa se enriquece com as contribuições e elaborações interpretativas de Norbert Elias. Ou seja, de uma questão associada aos altos índices de problemas sociais protagonizados pelos jovens, os pesquisadores foram levados a refletir sobre problemas que dizem respeito à própria sociedade.

Assim, as relações de poder e de status tomaram o centro da discussão, levandoos a buscarem explicar os porquês das diferenças de status e poder, inovando ricamente pela proposição de diretrizes conceituais elaboradas a partir do universo empírico numa escala deveras reduzida, dado o fato de Winston Parva ser uma comunidade de pequenas dimensões. Deste modo, como argumenta Neiburg (2000), a diminuta comunidade transformou-se num "verdadeiro laboratório para a análise sociológica".

Resta dizer, para finalizar meu esboço da constituição da obra, que a comunidade de Winston Parva apresentava uma clara divisão - embora parecesse, num primeiro olhar, relativamente homogênea -, considerando indicadores sociológicos correntes, como renda, educação, ocupação, religião etc.

Elias e Scotson caracterizaram os dois grupos sociais existentes como os "estabelecidos", moradores no local desde longa data (entre duas e três gerações) e os “outsiders", formados por residentes mais recentes, de no máximo vinte anos de ocupação. Estes últimos eram reconhecidos pelos hábitos trazidos da vida urbana na 
periferia de Londres, conflitando-se com o estilo de vida da comunidade tipicamente provinciana de Winston Parva.

Sendo assim, nessa pequena comunidade, observou-se a situação de estabelecidos-outsiders, ou seja, o grupo estabelecido atribuía a seus membros características humanas superiores, excluindo todos os membros do outro grupo do contato social não profissional e o controle social era mantido através das fofocas dos tipos elogiosa e depreciativa. Portanto, a relação de poder se definia com os estabelecidos ocupando posições de prestígio e de poder, se auto-percebendo e sendo reconhecidos como a "boa sociedade", mais poderosa e melhor, a partir de uma combinação singular de tradição, autoridade e influência.

Os outsiders são justamente as pessoas que se encontram totalmente fora deste tipo de situação (ELIAS E SCOTSON, 2000). ${ }^{1}$ Como afirmam os autores (2000, p. 20), depois de algum tempo, "esses próprios recém-chegados pareciam aceitar, com uma espécie de resignação e perplexidade, a ideia de pertencerem a um grupo de menor virtude e respeitabilidade", o que só se justificava, em termos de sua conduta efetiva, no caso de uma pequena minoria.

Nas palavras do próprio Elias (2000, p. 16), o estudo ilumina, num plano mais amplo, questões acerca dos "méritos e limitações dos estudos microssociológicos intensivos". Ainda de acordo com o autor, durante a realização da pesquisa, ele e Scotson surpreenderam-se ao constatarem com que "frequência as figurações e regularidades que [eram] desvendadas no microcosmos de Winston Parva sugeriam hipóteses que poderiam servir de guia até mesmo para levantamentos macrossociológicos" - o que chamaram de a "sociodinâmica da estigmatização", promovendo a construção de um modelo explicativo para uma figuração universal -, posto que questões maiores começaram a emergir, levando-os a observarem também "a maneira como um grupo de pessoas é capaz de monopolizar as oportunidades de poder e utilizá-las para marginalizar e estigmatizar membros de outro grupo muito semelhante" (2000, p. 13).

\section{A importância da história para pesquisa socioantropológica: o caso de Os Estabelecidos e os outsiders}

\footnotetext{
${ }^{1}$ Doravante apenas ano e página ou, quando couber, apenas a página como referência, dada a frequência sua recorrência ao longo do texto.
} 
No capítulo A formação das relações de vizinhança, os autores dão claras demonstrações de como a utilização da história é fundamental para a caracterização e a compreensão mais qualitativas dos aspectos sociológicos e antropológicos de uma pesquisa. Argumentam que a figuração, seu conceito fundamental do qual tratarei mais detidamente adiante, só pode ser entendida quando se trabalha com a perspectiva histórica. Isto porque, no caso em questão, trata-se do mecanismo fundamental para a compreensão de como dois grupos antes independentes tornaram-se, no processo de sua relação, interdependentes: de dois grupos genericamente estranhos entre si tornam-se grupos que só se definem quando em razão da reflexão sobre o outro.

Em regra, comunidades já estabelecidas e estruturadas esperam que as populações de imigrantes - portanto, os novatos - adaptem-se às formas por eles determinadas de comportamento, organização e enquadramento. Em Winston Parva tal cenário, isto é, o enquadramento dos recém-chegados, não se deu desta forma. Os "londrinos", denominação homogeneizadora e despersonalizada conferida pelos estabelecidos, mantiveram os hábitos originais de suas regiões e a opinião geral (dos estabelecidos) era de que a existência desses "bolsões de trabalhadores imigrantes" (2000, p. 63) foi com certeza uma das razões do status inferior atribuído ao loteamento como um todo, na classificação feita pelas zonas vizinhas.

Por hábitos, refiro-me tanto aos costumes, práticas e modos de agir da terra natal dos imigrantes quanto, a despeito do novo enraizamento, as formas destoantes de pensamento e, sob certo aspecto, a autonomia que tinham na mesma - é preciso lembrar que estes forasteiros não se deslocaram para lá apenas pelas possibilidades de emprego, mas especialmente porque Londres, durante a Segunda Guerra Mundial, estava sob cerrados bombardeios e muitos desses indivíduos haviam perdido muito ou tudo o que tinham.

Diante dessa recusa em enquadrar-se, rebaixando-se ou convertendo-se (e toda conversão é uma renúncia) aos modos locais, mais precisamente aos modos estabelecidos pelos locais, emerge, como maneira de reforçar essas fronteiras e como fonte de controle social dos eleitos indesejáveis, a ideia de tradição. Os "aldeões" ou estabelecidos desenvolveram, para otimizar seu fechamento interno, normas e padrões de comportamento, de linguagem etc., operando, para tanto, a constituição de uma memória histórica que os distinguia e, mais do que isso, os notabilizava. 
Nela, construiu-se, como forma de solidificar a referida distinção, uma mitologia histórica envolvendo o nome do fundador da comunidade, Charles Wilson, empreendedor da construção civil que por lá atuou durante os anos 1880. De acordo com essa mitologia, Wilson foi o patrono e desbravador daquelas paragens, tendo investido nas Zonas 1 e 2, dotando-as de sua excelência imaginada.

Do protagonismo de Wilson (sua inteligência - já que soube instalar-se e às suas construções de maneira, ao mesmo tempo, criativa e racional -, seu carisma - pois suas festas são narradas como históricas, memoráveis, como grandes acontecimentos -, e sua simpatia que, simbolicamente, contagiou e se incorporou ao espírito dos aldeões do passado e de seus descendentes), quase mitificado pelas narrativas compartilhadas microculturalmente pelos residentes mais antigos, valiam-se os mesmos, que, de certo modo, inspiravam-se e eram inspirados afetiva e emocionalmente pelo honroso fato de pertencerem à parte "nobre" da comunidade.

Não à toa, é mais uma vez o recurso à história que permite compreender, por uma construção real e/ou imaginária, a depreciação à Zona 3, densamente habitada pelos outsiders e, por assim dizer, um lugar outsider, posto que a mesma não foi projetada por Charles Wilson “por ser pantanosa e infestada de ratos” (2000, p. 62).

Assim, o próprio termo "aldeia" era o sinônimo de uma distinção conferida pela propriedade dos lugares e, extensivamente, da região como um todo. Isto é, aldeões eram aqueles que viviam nas partes mais antigas e que, portanto, eram também moradores antigos, verdadeiros guardiões das formas corretas de ser e de viver. Então, essa mesma antiguidade era composta, entre outras coisas, por supostos hábitos mais puros e retos e por uma linguagem mais polida, correta e inteligível (relembrando a fala de uma senhora entrevistada que afirmava que "não conseguia entender uma palavra do que eles [“os estrangeiros"] diziam").

Os aldeões, por serem mais antigos, eram os bastiões da tradição local e a manifestação mais explícita dessa tarefa auto-atribuída era um instrumental conhecimento das árvores genealógicas das pessoas mais antigas, de forma que cada indivíduo era situado na cadeia social local. A capacidade de traçar a trajetória de cada pessoa só podia, por motivos óbvios, ser manipulada pelos antigos, o que automaticamente projetava neste e no grupo ao qual ele pertencia uma propriedade de descrever a memória e a história locais, ainda que frutos de acontecimentos supostos ou 
mesmo inventados a fim de afirmar e reafirmar a todo o momento a especialidade e a superioridade de um grupo sobre o outro.

Em várias passagens, os autores nos mostram que a narração de fatos relativos à história local é, em dois níveis, fundamental:

1) porque reconstrói as trajetórias dos residentes dos dois loteamentos, de forma a situar a chamada sociodinâmica da estigmatização. Para eles (2000, p. 67), torna-se impraticável "compreender a estrutura da comunidade de Winston Parva descrita por expressões como 'antiga zona operária' e 'nova zona operária' sem fazer referência ao seu desenvolvimento", o que significa dizer, em termos metodológicos, que a distinção antigo-novo como parte do processo temporal é uma ferramenta fundamental na interpretação da realidade observada;

2) porque permite, como argumentado acima, que um caso específico e pontual, oriundo de pesquisa empírica, seja passível de generalização, tornando-se paradigma, no sentido de portar as estruturas mais básicas da diferenciação entre grupos humanos que não explicitam necessariamente características plausíveis de distinção.

De forma resumida, o que os autores nos informam é que a manutenção da distinção no caso estudado é explicável, em parte, pelo recurso àquilo que Hobsbawn e Ranger (1984) chamam de tradição inventada. ${ }^{2}$ Entretanto, essencial é perceber mais amplamente que a história recoloca a trajetória das pessoas como vinculadas ao todo da organização social. Isso significa dizer que estas são, ao mesmo tempo, influenciadas e influenciadoras dos acontecimentos sociais nos quais tomam parte, não sendo, portanto, simples repositórios das regras e normas construídas acima delas. Elas participam de sua construção e, mais do que isso, as atualizam incessantemente, adequando-as à realidade vivida.

Por isso, Elias e Scotson primam pela reconstrução de que tanto chamei a atenção aqui: ao contrário do corolário reinante à época, a história reorganiza a estrutura, conferindo-lhe inteligibilidade e sentido. Tal argumento, parece-me, está sincronizado com os delineamentos posteriores (ainda que construídos para outras finalidades) de Marshall Sahlins (1990), onde este, como aqueles, aposta no caráter

\footnotetext{
${ }^{2}$ Hobsbawn e Ranger (1984, p. 9) dão ao termo o sentido de que as "tradições" que parecem ou são consideradas antigas existem, na verdade, de forma muito recente, quando não são inventadas. Trata-se de um conjunto de práticas que visam inculcar certos valores e normas de comportamento através da repetição, implicando, automaticamente, uma continuidade em relação ao passado.
} 
processual da mudança: para apreender a realidade de um certo momento é fundamental conhecer como se deu sua evolução.

Não se trata, ao fazer esse exercício, portanto, de acordo com uma analogia utilizada por Elias para criticar a teoria parsoniana da ação, de realizar uma "fotografia", mas sim, utilizando-me livremente de um termo de Guattari e Rolnik (1986), de desvendar uma cartografia.

Termino este tópico reproduzindo uma ilustrativa passagem do texto, que certamente reifica a importância do recurso à história na tentativa de reconstruir aproximadamente os nexos e direcionamentos que estruturam a vida social de um grupo e sua relação com os demais

\begin{abstract}
A reconstituição da situação inicial dos dois grupos e do desenvolvimento de sua relação ajudou a compreender o padrão estável que esta havia adquirido na época da pesquisa. Era preciso um certo conhecimento de como essa relação fora gerada para entender de que modo os habitantes da Zona 2 puderam reivindicar para si, com sucesso, um status mais elevado que os da Zona 3, ao mesmo tempo que, por seu turno, atribuíam um status mais alto à maioria dos residentes da Zona 1; e, sem esclarecer e explicar essa ordem hierárquica, ficava-se sem a chave para compreender outros aspectos da vida comunitária (ELIAS e SCOTSON, 2000, p. 64).
\end{abstract}

\title{
Discutindo sociedade e cultura em Os Estabelecidos e os outsiders
}

Como ocorre com o tópico sobre a história, os autores dedicam-se a discutir noções e modelos de leitura sobre a sociedade e a cultura. Contudo, se programaticamente eles se esforçaram para clarificar a diferencial forma pela qual a história é introduzida num estudo etnográfico como este, afastando-se, como já disse, do modelo da ação e da estrutura propugnados em especial por Talcott Parsons, nesse par de noções não há, de forma clara e inconfundível, separação conceitual entre ambas. $\mathrm{O}$ que se encontra, creio, são exemplos de maneiras de se abordar cada um desses níveis no estudo, o que, alerto, em nada empobrece o mesmo.

Para tanto, ao tratar particularmente de sociedade, inspirando-se nas características gerais de Winston Parva, os autores focam na distribuição do poder pelos canais institucionalizados. Assim, os estabelecidos exploram os postos e as formas de assunção das posições de destaque comunitário, seja na política ou nas associações beneficentes, seja nos conselhos comunitários ou na participação dos eventos públicos 
dos clubes e afins, dos quais em regra os outsiders não tinham uma participação proeminente ou sequer participavam.

Uma dimensão importante que auxilia na caracterização deste cenário, é a noção de cotidiano que pode ser implicitamente encontrada na obra. Por cotidiano entende-se "as práticas realizadas pelos atores sociais no seu dia a dia, que não se resumem, contudo, à mecanicidade da rotina" (MEDEIROS, 2007, p. 176). Tais ações, apesar de serem vistas, na maioria das vezes, como algo banal ou insignificante, compõem um campo extremamente frutífero para o desenvolvimento das relações sociais e, consequentemente, de estudos sobre a sociedade.

Dentre as principais características do cotidiano, pode-se apontar a probabilidade, a espontaneidade, a sociabilidade, a polissemia e a heterogeneidade nas relações humanas.

Como propositores, na obra, de uma sociologia do cotidiano, a dimensão do poder aparece como carro chefe das relações entre os integrantes dos dois grupos, como declara o subtítulo do livro. Vislumbrando esse cotidiano, os autores apontam que, quando o diferencial de poder é suficientemente grande, um membro de um grupo estabelecido pode, em suas práticas sociais, "ser indiferente ao que os outsiders pensam dele, mas raramente ou nunca é indiferente à opinião de seus pares" (ELIAS E SCOTSON, idem, p. 40).

Nesse sentido, completam, "a auto-imagem e a auto-estima de um indivíduo estão ligadas ao que os outros membros do grupo pensam dele" (2000, p. 40). Com isso, sua proposição é de que a imagem do homem que é necessária para o estudo das ciências sociais, em particular da sociologia, não é o da pessoa no singular, mas sim a de pessoas no plural de modo a conceber a imagem de uma multidão de pessoas, cada uma delas formando um processo aberto e interdependente. Processo que constitui pessoas entre outras pessoas, envolvidas em jogos com outras pessoas, formando configurações que podem alterar-se no decorrer da evolução social por intermédio dos conflitos e tensões que perfazem o centro do processo de evolução de sua teoria sociológica.

O modelo teórico dos autores para a discussão do social considera essencial, então, a ideia de interpenetração e de interdependência (e, desta forma, é possível perguntar-se o que faz as pessoas ligarem-se umas as outras se tornando mutuamente dependentes) para mostrar um nível de integração em que as formas de organização, 
processos e estruturas não podem ser deduzidas das características biológicas e psicológicas que formam os indivíduos.

Daí alguns autores como Matos e Gebara (2007, p. 190) falarem em processos psicogenéticos e sociogenéticos de sistematização de controles, através dos quais se torna possível balizar o estágio de desenvolvimento da sociedade, já que o que se propõe é um exame rigoroso do papel desempenhado pela imagem que cada pessoa faz da posição de seu grupo e de seu próprio status como membro pertencente a esse grupo. Para tanto, a importância do conceito de figuração é indiscutível.

O conceito, elaborado por Elias já em outras obras como O Processo Civilizador e A Sociedade de Corte e aqui retomado, é citado e discutido repetidas vezes ao longo do livro, compondo a coluna vertebral desse estudo empírico. Textualmente, o conceito de figuração diz sobre a rede de interdependências formada pelos indivíduos, cujo conjunto será denominado de configuração. Estas, que podem ser internas ou externas a um determinado grupo, são consequências inesperadas das inúmeras possibilidades de interações sociais vividas pelo indivíduo ou pelo grupo. O poder está situado sempre como elemento fundamental de qualquer configuração.

O estudo da sociedade não se explica ao estudarmos os seres humanos isoladamente, mas sim as configurações de seres humanos interdependentes, por ele entendidas como uma espécie de padrão mutável criado pelo conjunto dos jogadores, não somente pelos seus intelectos mas pelo que eles são na totalidade das suas ações e relações que sustentam reciprocamente, possibilitando a formação de uma teia flexível de tensões.

Elias acrescenta que o conceito de configuração é mais apropriado e frutífero para esclarecer o que chama de "sociedade", exemplificando metafórica e poeticamente: "as mesmas configurações podem certamente ser dançadas por diferentes pessoas, mas, sem uma pluralidade de indivíduos reciprocamente orientados e dependentes, não há dança" (ELIAS, 1994, p. 250). Traçando, como conceituação geral um aspecto retirado de Winston Parva, afirma que "a possibilidade de um grupo afixar em outro um rótulo de inferioridade humana e fazê-lo prevalecer era função de uma figuração específica que os dois grupos formavam entre si” (ELIAS e SCOTSON, 2000, p. 23).

Resta dizer, com base em Sallas (2001, p. 218), que a análise configuracional possui duas características fundamentais: "são modelos didáticos que devem ser interpretados como representações de seres humanos ligados uns aos outros no tempo e 
no espaço" e ainda "servem para romper com as polarizações clássicas dentro da sociologia, que tendem a pensar o 'indivíduo' e a 'sociedade' como formas antagônicas e diferentes."

Enfim, de acordo com Elias (1994, p. 184)

\begin{abstract}
dizer que os indivíduos existem em configurações significa que o ponto de partida de toda a investigação sociológica é uma pluralidade de indivíduos, os quais, de um modo ou de outro, são interdependentes. Dizer que as configurações são irredutíveis significa que nem se pode explicá-las em termos que impliquem que elas têm algum tipo de existência independente dos indivíduos, nem em termos que impliquem que os indivíduos, de algum modo, existem independentemente delas.
\end{abstract}

A transcrição acima abre uma importante e valiosa seara da teoria eliasiana sobre a sociedade a ser explicada: as noções de indivíduo e sociedade. Ele trabalha tais noções como, mais uma vez, processos interdependentes, onde a rede de interdependências é o que nos liga uns aos outros, de maneira a formar o nexo da configuração, ou seja, "uma estrutura de pessoas mutuamente orientadas e dependentes" (ELIAS, 1994, p. 249).

Desse modo, faz sentido entender a relação entre estas duas entidades como um conceito que se refere à pessoa no singular, o outro, e as pessoas no plural respectivamente. Trata-se, portanto, de uma crítica, ao mesmo tempo, às teorias atomísticas e holísticas que ora imaginam a existência de indivíduos isolados, ora um "todo social" pairando sobre os seres humanos.

Distinguir estes níveis, ou melhor, aproximá-los e distanciá-los simultaneamente, ao gosto do jargão da teoria de Norbert Elias, desvela outro elemento central nos estudos configuracionais, o de que ele se assenta nas dimensões do poder, dos comportamentos e das emoções. A rede de relações entre seres humanos, cuja natureza é não ser planificável, mas sim mutável, faz com que o equilíbrio de poder seja de tendência a transformar-se constantemente, de forma assimétrica, não dicotômica entre autores e atores, entre indivíduo e sociedade.

No âmbito da cultura, Elias aparentemente se aproxima dos teóricos que apostam na relação interativa como produtora de símbolos e de concepções acerca da realidade. Nesse sentido, o estudo é o das interações, não das substâncias. Isso equivale a dizer, mais uma vez, que os processos, os fragmentos que o compõem, é que são os fatos observáveis. A realidade é móvel e se estrutura de maneira contrastiva. O que 
captamos são as redes de relações que formam o ethos de cada lugar e não as relações em si mesmas.

Assim, nessa como em outras obras, reafirma-se insistentemente o cuidado de uma análise baseada na forma como se deu o processo de mudança nos costumes, e não se são melhores ou piores do que os anteriores. Interessa-lhe, como já afirmei, a captação da fase de um desenvolvimento social que, por ser processual, só pode ser apreendida na sua manifestação atual, após o entendimento da sua trajetória histórica, não servindo, portanto, para fazer projeções e testes quanto à sua forma de apresentação futura mas apenas ajudar na elaboração de políticas e no desenvolvimento de práticas de aprimoramento. ${ }^{3}$

Parece haver, nesse tema, o da cultura, uma consistente aproximação entre Elias e Frederik Barth. ${ }^{4}$ Em Barth, a ênfase se dá na ideia de complementariedade. Isto é, as sociedades são formadas por grupos distintos e opositores, o que significa afirmar que "classe dominante" e "classe dominada" só existem em função de sua intestinal interrelação. Para Elias, o mesmo se pode dizer através do já discutido conceito de figuração.

Até mesmo o poder, seja ele no campo político, econômico, cognitivo etc., que supostamente tem um peso insuportável para o subjugado, deve ter sua manifestação lida como objeto de interpretação quanto à relatividade: ele deixa de ser uma substância para se transformar numa relação entre duas ou mais pessoas, passando a ser um atributo destas relações que se mantêm, na maior parte das vezes, num equilíbrio instável de forças.

Exemplificando o poder na teoria de Elias, e entendendo-o como aspecto relacional nas práticas culturais tecidas no interior das sociedades, este não se resume ao que ocorre entre senhores e servos ou dominadores e dominados: pode ocorrer entre indivíduos de uma mesma família ou entre membros de bairros vizinhos. Pode mostrarse também nas mais variadas situações, como a maneira que os indivíduos se portam à mesa, a maneira de se vestir e a aceitação (ou não) em atividades cotidianas de lazer.

\footnotetext{
${ }^{3}$ É intrigante a passagem (ELIAS e SCOTSON, 2000, p. 34), que parece se coadunar com a questão da dominação simbólica ainda vigente entre muitos grupos de estabelecidos e de outsiders no mundo de hoje: “...ainda não se aprendeu a lição de que, num mundo cada vez mais interdependente, a dominação de um setor da humanidade sobre os outros está fadada a ter um efeito de bumerangue."

${ }^{4}$ Cf. especialmente a discussão que tem lugar no capítulo "A análise da cultura nas sociedades complexas" (BARTH, 2000).
} 
Os autores aprofundam outras duas ocorrências importantes: a questão do autoreconhecimento negativo e da identidade, campos inequivocamente interrelacionados na imagem comunitária normativa. A questão do auto-reconhecimento negativo refere-se à assunção, à incorporação, pelos outsiders, do lugar em que declaradamente os colocam os estabelecidos.

Ao mesmo tempo em que os estabelecidos transformavam um fato único ocorrido no loteamento em uma característica genérica (e mesmo genética) dos outsiders, estes, ao fim, se auto-reconheciam como possuidores de um "valor humano inferior". No caso da delinquência juvenil, objeto original do estudo, o sentimento de exclusão fazia com que partes da população estigmatizada - os jovens - incorporassem esta exclusão de modo a se manifestarem negativamente, ativando os rótulos que lhes eram imputados. ${ }^{5}$

Se, de um lado, o sentimento de ser inferior vai sendo apropriado pelos próprios membros do grupo excluído, seja pela mediação de palavras ou pelos termos que são simbolicamente depreciativos, por outro, era exatamente isso que forjava a identidade de ambos os grupos, transformando-se em poderosas armas para que o grupo estabelecido preservasse sua identidade, afirmando diuturnamente sua superioridade, a medida que esse verdadeiro sistema de funcionamento se estruturava.

A incrustação do rótulo de "valor humano inferior" nos segmentos outsiders tinha sua eficácia por conseguir penetrar na auto-imagem destes, enfraquecendo-os e desarmando-os. Como dizem os Elias e Scotson (2000, p. 30): "Dê-se a um grupo uma reputação ruim e é provável que ele corresponda a essa expectativa".

Ainda no quesito identidade, importa relembrar que, no processo de captação dos dados, por meio de entrevistas ou noutros contextos, ficou patente que as respostas representavam variações individuais das crenças e atitudes padronizadas que circulavam nessas áreas.

Como sugestão de pesquisa, parece pertinente repisar esta mensagem pois, tendo por horizonte um modelo configuracional como o de Elias, deve-se considerar que o ideal da racionalidade na condução das questões humanas ainda obstaculiza o acesso à estrutura e à dinâmica das figurações estabelecidos-outsiders, assim como às fantasias

\footnotetext{
${ }^{5}$ Seria interessante tentar contrastar esse quadro de assunção "forçada" de um lugar e de uma humanidade inferior na composição da comunidade de Winston Parva e aquela discutida por Foote-Whyte em que o objetivo era exatamente oposto: reafirmar-se pela "fama de mau" (FOOTE-WHYTE, 2005, especialmente capítulos 1 e 2).
} 
grupais de grandeza suscitadas por elas, e que são "dados sociais sui generis, nem racionais nem irracionais." (ELIAS e SCOTSON, 2000, p. 36-7).

\section{Conclusão}

Das colocações expressas ao longo deste texto, desejo finalizar resgatando de maneira mais informal algumas percepções, orientações e ensinamentos para reflexão no ato da pesquisa e da escrita em Ciências Sociais.

No que tange ao livro Os estabelecidos e os outsiders como documento teórico e metodológico importante para a pesquisa científica, é interessante relembrar que, segundo Elias, nós pensamos constantemente a partir do foco de diferenças tais como as de sexo, de cor, de classe, de nação, entre outras, como diferenciais estruturais das relações de poder. Isso faz com que dificilmente cheguemos a problematizar questões em que estão colocados os termos da igualdade ou que o diferencial de poder possa estar associado ao tempo de residência em certo lugar e ao maior ou menor grau de coesão e organização de cada grupo interrelacionado.

Para Elias e Scotson (2000, p. 180-181), ainda nessa linha, "não há justificativa para considerar as investigações sociológicas do que se julga serem formas de 'mau funcionamento', ou como se diz, de 'disfunção"', como um grupo distinto do que é "formado por aquilo que se julga 'funcionar bem'". Visto desse modo, não se pode esperar encontrar explicações para “o que se julga 'ruim', para um 'mau funcionamento' da sociedade, quando não se é capaz de explicar, ao mesmo tempo, aquilo que se avalia como 'bom', 'normal' ou 'funcionando bem', e vice-versa”.

Como defende Sallas (2001, p. 219), tal aspecto evidencia uma característica da sociologia de Elias, que é a de estar pronta para "refletir criticamente sobre as categorias sociológicas que se apresentam de modo 'naturalizado', como se se tratassem de realidades inevitáveis e eternas."

Nas palavras de Sallas 2001 (p. 57),

[...] ainda não é parte integrante da formação dos sociólogos [e acho que se pode acrescentar dos cientistas sociais mais amplamente] aprender a observar e conceituar sistematicamente o modo como os indivíduos se agregam, como e porque eles formam entre si uma dada configuração ou como e porque as configurações assim formadas se modificam e, em alguns casos, se desenvolvem. 
Como ensinamento geral, o livro nos diz que conceitos como poder, norma, valor, estrutura e função, classe social e sistema social, sociedade e indivíduo, devem ser encarados pelos sociólogos como categorias mutáveis e móveis. Isto porque a sociologia não deve fazer a redução processual daquilo que observa como sendo móvel e mutável a algo imutável e eterno.

Diz também, posicionando-se ao lado do tipo de pesquisa que chamamos comumente de qualitativa, que é um fato conhecido de outras pesquisas, ainda que, talvez, não suficientemente salientado, que "os dados sociais podem ser sociologicamente significativos sem ter significação estatística e podem ser estatisticamente significativos sem ter significação sociológica." (ELIAS e SCOTSON, 2000, p. 59)

A leitura de Os estabelecidos e os outsiders ilumina um ponto que não é, em meu entendimento, exaustivo repetir, pois une os elementos de história, sociedade e cultura no argumento de Elias. Gostaria de, com ele, fechar este trabalho.

Trata-se do fato de o autor identificar a ocorrência da diferenciação, em Winston Parva, como uma "constante universal". Nela, o grupo estabelecido atribui aos seus membros características humanas superiores, excluindo todos os membros do outro grupo de contato social não profissional com seus próprios.

Produz-se, com isso, um tabu em torno desses contatos que se perpetua através de meios de controle social como a fofoca elogiosa no caso dos que o observavam e a ameaça de fofocas depreciativas contra os suspeitos de transgressão.

Atravessando todo o livro, este argumento deixa entrever a última e mais instigante questão quando se trata de trabalhar com uma realidade micro como a da comunidade de Winston Parva: o exame da relação entre episódios específicos e o desenvolvimento global das sociedades nos tempos modernos.

Para nosso autor, nós, cientistas sociais, somos frequentemente mais passíveis de perceber as questões que estão ligadas a estes microcosmos como uma multiplicidade de problemas sociais locais do que de encará-las como um problema sociológico. Será?!

\section{Referências}

BARTH, Frederik. A análise da cultura nas sociedades complexas. In: LASK, Tomke (org.). O Guru, o iniciador e outras variações antropológicas, RJ: Contracapa, 2000. 
ELIAS, Norbert e SCOTSON, John L. Os estabelecidos e os outsiders, RJ: Jorge Zahar Editor, 2000.

ELIAS, Norbert. O processo civilizador, vol. I (Uma história dos costumes), RJ: Jorge Zahar Editor, 1994.

FOOTE-WHYTE, William. A sociedade de esquina, RJ: Jorge Zahar Editor, 2005.

GUATTARI, Félix e ROLNIK, Suely. Cartografias do desejo, Petrópolis: Vozes, 1986.

HOBSBAWN, Eric e RANGER, Terence (orgs.). A invenção das tradições, RJ: Paz e Terra, 1984.

MATOS, Eloiza Aparecida Silva Ávila de e GEBARA, Ademir. Tecnologia e história: Johan Goudsblom e Norbert Elias. Revista Gestão Industrial, nº. 3, vol. 3, Curitiba: UTFPR, 2007.

MEDEIROS, Patrícia Lins Gomes de. "Aspectos do poder e do cotidiano em Norbert Elias”. In: EmTese, nº. 2, vol. 3, Florianópolis: UFSC, janeiro-julho/2007.

NEIBURG, Frederico. A sociologia das relações de poder de Norbert Elias. In: ELIAS, Norbert e SCOTSON, John L. Os estabelecidos e os outsiders, RJ: Jorge Zahar Editor, 2000 .

SAHLINS, Marshall. Ilhas de História, RJ: Jorge Zahar Editor, 1990.

SALLAS, Ana Luiza Fayet. Resenha de ELIAS, Norbert \& SCOTSON, John L. Os estabelecidos e os outsiders: sociologia das relações de poder a partir de uma pequena comunidade, RJ: Jorge Zahar Editor, 2000. Campos, revista de antropologia social, vol 1, Curitiba: UFPR, 2001. Disponível em <http://calvados.c3sl.ufpr.br/ojs2/index.php/campos/article/viewPDFInterstitial/1561/13 09. Acessado em 11 jan. 2011. 